\title{
CAKUPAN $A N C$ DAN CAKUPAN TABLET FE HUBUNGANNYA DENGAN PREVALENSI ANEMIA DI JAWA TIMUR
}

\author{
Sylvi Natalia ${ }^{1}$, Sri Sumarmi², Siti Rahayu Nadhiroh ${ }^{2}$ \\ ${ }^{1}$ Program Studi Ilmu Gizi Fakultas Kesehatan Masyarakat Universitas Airlangga, Surabaya \\ ${ }^{2}$ Departemen Gizi Kesehatan, Fakultas Kesehatan Masyarakat Universitas Airlangga, Surabaya \\ E-mail: nataliasylvi@gmail.com
}

\begin{abstract}
ABSTRAK
Suplementasi Fe merupakan program penanggulangan anemia di Indonesia. Indikator keberhasilan program tersebut menggunakan cakupan Antenatal Care (ANC) dan cakupan tablet Fe. Penelitian ini bertujuan untuk menganalisis hubungan antara cakupan ANC dan cakupan tablet Fe dengan prevalensi anemia ibu hamil di Jawa Timur tahun 2015. Penelitian ini mengolah data sekunder dari hasil laporan Seksi Gizi dan Seksi Kesehatan Keluarga Dinas Kesehatan Provinsi Jawa Timur. Metode analisis data menggunakan uji korelasi pearson. Rata-rata prevalensi anemia ibu hamil di Jawa Timur sebesar 5,8\%, hasil tersebut masih di bawah target nasional yaitu sebesar 28\%. Hasil penelitian menunjukkan tidak ada hubungan antara cakupan ANC dan tablet Fe dengan prevalensi anemia $(p-v a l u e>0,05)$. Kesimpulan yang diperoleh bahwa cakupan pemberian tablet Fe kepada ibu hamil melalui pelayanan ANC tidak menggambarkan besar kecilnya prevalensi anemia ibu hamil karena yang mempengaruhi anemia meliputi banyak faktor seperti bioavaibilitas zat besi, dan kepatuhan ibu hamil mengonsumsi zat besi.
\end{abstract}

Kata kunci: anemia, cakupan $\mathrm{ANC}$, tablet Fe

\section{ABSTRACT}

Iron supplementation is one of the anemia prevention program in Indonesia. Success Indicator of its program is ANC coverage and coverage of iron tablet distribution. This study aimed to analyze the relationship between the ANC (Antenatal Care) and iron tablet coverage with prevalence of anemia among pregnant women in East Java year 2015. This research used data report from Nutrition Division and Family Health Division of Provincial Health Office East Java. Data was analyse using Pearson correlation test. The prevalence of anemia among pregnant women in East Java was $5.8 \%$, the result are still below the national target which is $28 \%$. The result showed that there was no relationship between the ANC and iron tablet coverage with the prevalence of anemia (p-value $>0.05$ ). It is concluded that coverage of iron supplementation among pregnant women through ANC does not describe the prevalence of anemia among pregnant women due to many factors that influence anemia such as bioavailability of iron and compliance pregnant women consume iron.

Keywords: anemia, ANC coverage, iron tablet

\section{PENDAHULUAN}

Kekurangan zat besi atau anemia pada ibu hamil merupakan salah satu faktor risiko yang penting dalam kesehatan. Menurut WHO (2015), prevalensi anemia di Indonesia sebesar 23\%. Berdasarkan Riskesdas (2013), terdapat 37,1\% ibu hamil anemia, yaitu ibu hamil dengan kadar $\mathrm{Hb}$ kurang dari 11,0 gram/dl, dengan proporsi yang hampir sama antara di kawasan perkotaan $(36,4 \%)$ dan perdesaan $(37,8 \%)$. Infodatin Gizi (2015) menyebutkan diperkirakan 41,8\% ibu hamil di seluruh dunia mengalami anemia.

Peraturan Menteri Kesehatan RI nomor 88 tahun 2014 menjelaskan program suplementasi tablet $\mathrm{Fe}$ untuk mengatasi kekurangan konsumsi zat besi, yaitu pemerintah membuat program suplemen tambah darah kepada setiap ibu hamil sebanyak 90 tablet selama kehamilan.

Berdasarkan data laporan Profil Kesehatan Indonesia tahun 2014, rata-rata cakupan pemberian tablet Fe-3 Nasional adalah 85,1\% dan rata-rata cakupan pemberian tablet Fe-3 di Provinsi Jawa Timur masih di bawah rata-rata Nasional yaitu sebesar 84,9\%. Data dalam Profil Kesehatan Provinsi Jawa Timur tahun 2012 melaporkan cakupan kunjungan ibu hamil di Provinsi Jawa Timur untuk K1 sebesar 96,19\% dan cakupan kunjungan ibu hamil K4 sebesar 88,66\%. Cakupan 
Antenatal Care (ANC) di Provinsi Jawa Timur tersebut juga masih tergolong di bawah rata-rata dari angka cakupan nasional yaitu $97,86 \%$ dan $89,33 \%$.

Distribusi tablet $\mathrm{Fe}$ melalui kegiatan pelayanan Antenatal Care (ANC) belum berjalan optimal disebabkan beberapa hal. Irawati (2012) menyebutkan pelaksanaan distribusi tablet Fe masih belum berjalan optimal yang disebabkan kurangnya ketersediaan tenaga kesehatan, ketersediaan tablet $\mathrm{Fe}$ yang mengalami kekosongan maupun kelebihan, dan tidak tersedianya dana operasional dalam melaksanakan kegiatan distribusi tablet Fe. Irawati (2012) juga menyebutkan rendahnya cakupan pemberian tablet Fe disebabkan kurang optimalnya koordinasi dengan lintas program KIA khususnya pelayanan ANC (Antenatal Care). Dengan meningkatnya cakupan ANC (K1 dan K4) dan cakupan tablet Fe, diharapkan dapat menurunkan angka prevalensi anemia ibu hamil sehingga perlu dilakukan kajian lebih lanjut mengenai program tersebut dengan melakukan analisis hubungan cakupan ANC dan cakupan pemberian tablet $\mathrm{Fe}$ dengan prevalensi anemia ibu hamil di Provinsi Jawa Timur.

\section{METODE}

Penelitian ini merupakan jenis penelitian kuantitatif dengan menggunakan data sekunder dari hasil laporan tingkat Kabupaten/Kota terdiri dari data cakupan $\mathrm{K} 1$ dan $\mathrm{K} 4$, data pemberian tablet $\mathrm{Fe}-1$ dan $\mathrm{Fe}-3$ serta data prevalensi anemia ibu hamil dengan $\mathrm{Hb}<11 \mathrm{~g} / \mathrm{dl}$ yang tercatat di Seksi Gizi dan Seksi Kesehatan Keluarga Dinas Kesehatan Provinsi Jawa Timur. Analisa data menggunakan uji statistik Korelasi Pearson untuk menyatakan ada tidaknya hubungan yang signifikan antara variabel independen yaitu cakupan ANC dan cakupan tablet Fe dengan variabel dependen yaitu prevalensi anemia ibu hamil. Penelitian ini telah memperoleh persetujuan etik dari Komisi Etik penelitian kesehatan Fakultas Kesehatan Masyarakat Universitas Airlangga no: 188-KEPK/2016.

\section{HASIL DAN PEMBAHASAN}

\section{Prevalensi Anemia Ibu Hamil}

Prevalensi anemia ibu hamil di Propinsi Jawa Timur tahun 2015 dapat dilihat pada Gambar 1.

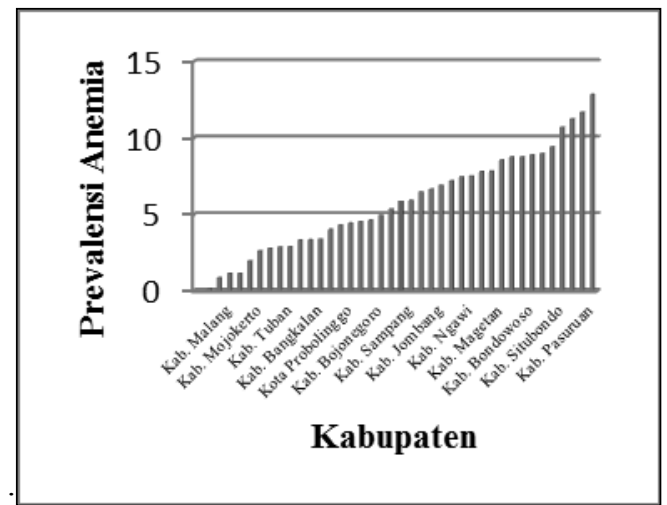

Gambar 1. Prevalensi Anemia Ibu Hamil di Provinsi Jawa Timur tahun 2015.

Berdasarkan Gambar 1. menunjukkan bahwa prevalensi anemia ibu hamil diatas 10\% diperoleh 4 Kabupaten/Kota yaitu Kabupaten Situbondo sebesar 10,69\%, Kota Mojokerto sebesar 11,23\%, Kabupaten Madiun sebesar 11,66\% dan Kabupaten Pasuruan sebesar 12,83\%. Rata-rata prevalensi anemia di Provinsi Jawa Timur sebesar 5,8\%. Rata-rata prevalensi anemia di Provinsi Jawa Timur tersebut masih dibawah target Nasional yaitu sebesar 28\% (RPJMN 2015-2019). WHO (2001) menyebutkan klasifikasi prevalensi anemia untuk suatu daerah berdasarkan tingkat masalah yaitu berat $\geq 40 \%$, sedang $20 \%-39,9 \%$, ringan $5 \%$ $19,9 \%$ dan normal $\leq 4,9 \%$.

Berdasarkan klasifikasi tersebut 21 Kabupaten/ Kota di Jawa Timur masuk dalam daerah dengan klasifikasi ringan dan 17 Kabupaten/Kota lainnya masuk dalam daerah dengan klasifikasi normal. Rata-rata prevalensi anemia di Provinsi Jawa Timur masuk dalam daerah dengan klasifikasi ringan. Vita (2014) juga menyebutkan bahwa ibu hamil yang mengalami anemia gizi di Jawa Timur sebanyak 24 orang $(25,3 \%)$, dengan persentase ibu hamil yang menderita anemia terjadi pada 
kelompok ibu hamil dengan KEK (Kurang Energi Kronis). Menurut Stoltzfus (1998) daerah dengan prevalensi anemia ibu hamil $<40 \%$, seorang ibu hamil harus mengonsumsi tablet $\mathrm{Fe}$ yang mengandung $60 \mathrm{mg}$ zat besi dan $400 \mu \mathrm{g}$ asam folat selama 6 bulan kehamilan dan dilanjutkan 3 bulan setelah melahirkan. Apabila selama kehamilan kebutuhan tablet $\mathrm{Fe}$ tidak bisa terpenuhi, maka harus dilanjutkan dengan pemberian tablet $\mathrm{Fe}$ yang mengandung $120 \mathrm{mg}$ zat besi selama 6 bulan setelah melahirkan.

\section{Cakupan ANC}

Hasil penelitian cakupan K1 dapat dilihat dalam Gambar 2.

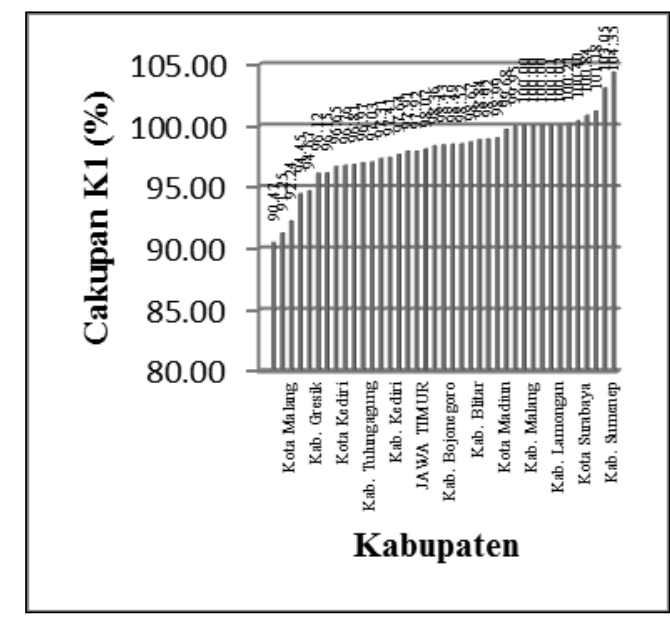

Gambar 2. Cakupan Kunjungan Ibu Hamil K1 di Propinsi Jawa Timur tahun 2015.

Berdasarkan Gambar 2, menunjukkan bahwa 11 Kabupaten/Kota sudah mencapai target $100 \%$. Cakupan kunjungan ibu hamil K1 untuk 27 Kabupaten/Kota lainnya memperoleh cakupan di bawah $100 \%$. Cakupan kunjungan ibu hamil K1 terendah diperoleh Kabupaten Nganjuk, Kota Blitar, Kota Malang, dan Kabupaten Pacitan. Ratarata cakupan kunjungan ibu hamil K1 di Provinsi Jawa Timur sebesar 98,07\%. Angka tersebut belum bisa mencapai target nasional yaitu sebesar 100\%. Cakupan K1 menunjukkan keterjangkauan terhadap pelayanan Antenatal Care (ANC).

Hasil penelitian cakupan K4 dapat dilihat dalam Gambar 3. Gambar 3 menunjukkan bahwa 6 Kabupaten/Kota mempunyai cakupan

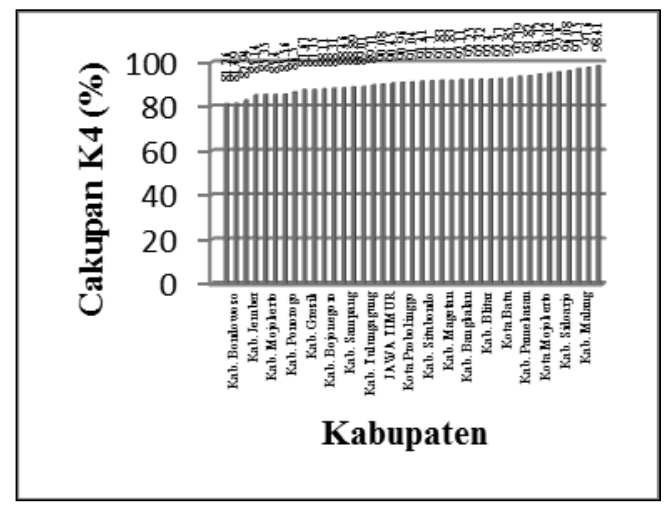

Gambar 3. Cakupan Kunjungan Ibu Hamil K4 di Propinsi Jawa Timur tahun 2015.

kunjungan ibu hamil K4 diatas 95\%. Data cakupan kunjungan ibu hamil K4 terendah diperoleh Kabupaten Nganjuk dan diikuti 31 Kabupaten/ Kota lainnya dengan cakupan di bawah 95\%. Rata-rata cakupan kunjungan ibu hamil K4 di Provinsi Jawa Timur sebesar 90,44\%. Rata-rata tersebut belum bisa mencapai target nasional yaitu 95\%. Angka rata-rata cakupan K1 dan K4 di Jawa Timur belum mencapai target yaitu $100 \%$ untuk cakupan K1 dan 95\% untuk cakupan K4 (Depkes RI, 2013). Angka tersebut menunjukkan bahwa akses petugas kesehatan (bidan) kepada ibu hamil masih perlu ditingkatkan. Dalam penelitian Fitrayeni (2015) menyebutkan bidan juga mempunyai pengaruh terhadap cakupan ANC dan kelengkapan kunjungan ANC. Agustini (2013) menjelaskan bahwa cakupan ANC dipengaruhi oleh tingkat pengetahuan dan dukungan keluarga. Ritonga (2012) juga menyebutkan faktor yang mempengaruhi pemeriksaan kehamilan antara lain pengetahuan, pendidikan, akses keterjangkauan dan dukungan keluarga

\section{Cakupan Tablet Fe}

Hasil penelitian cakupan tablet Fe-1 dapat dilihat dalam Gambar 4. Gambar 4 menunjukkan bahwa terdapat 6 Kabupaten/Kota memperoleh cakupan pemberian tablet $\mathrm{Fe}-1$ diatas $100 \%$. Data cakupan pemberian tablet $\mathrm{Fe}-1$ untuk 32 Kabupaten/Kota lainnya berada di bawah $100 \%$. Cakupan pemberian tablet $\mathrm{Fe}-1$ terendah diperoleh Kabupaten Mojokerto, Kota Kediri, Kota Blitar dan rata-rata cakupan pemberian $\mathrm{Fe}-1$ di Provinsi Jawa Timur sebesar 96,4\%. 


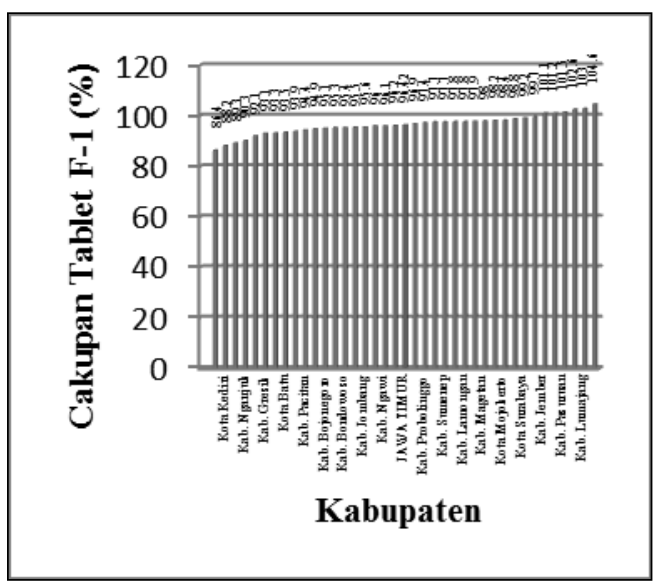

Gambar 4. Cakupan Pemberian Tablet Fe-1 di Propinsi Jawa Timur tahun 2015.

Hasil penelitian cakupan tablet Fe-3 dapat dilihat dalam Gambar 5. Gambar 5 menunjukkan bahwa 2 (dua) Kabupaten/Kota memperoleh cakupan pemberian tablet $\mathrm{Fe}-3$ diatas $95 \%$ yaitu Kota Mojokerto dan Kota Madiun, sedangkan untuk 36 Kabupaten/Kota lainnya diperoleh cakupan pemberian tablet $\mathrm{Fe}-3$ di bawah $95 \%$. Dua Kabupaten di Jawa Timur diperoleh cakupan pemberian tablet $\mathrm{Fe}-3$ terendah yaitu Kabupaten Mojokerto sebesar 80,4\% dan Kota Blitar sebesar $80,8 \%$. Rata-rata cakupan pemberian tablet $\mathrm{Fe}-3$ di Provinsi Jawa Timur sebesar $89,1 \%$.

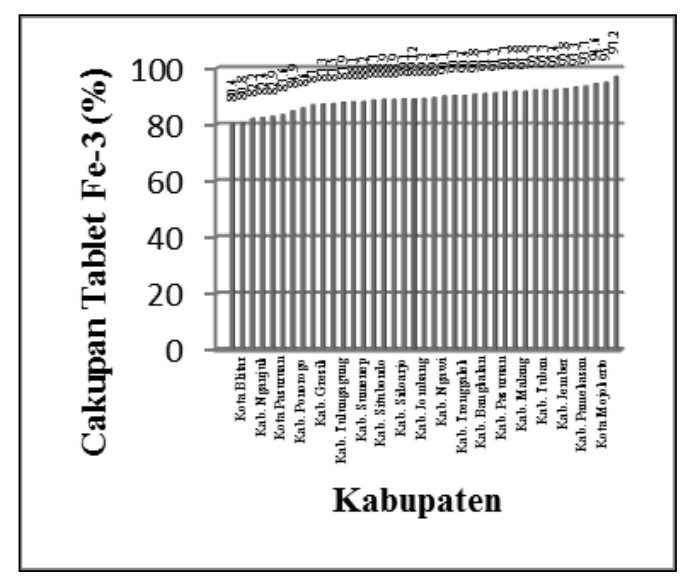

Gambar 5. Cakupan Pemberian Tablet Fe-3 di Propinsi Jawa Timur tahun 2015.
Hasil di atas menunjukkan bahwa beberapa Kabupaten/Kota di Provinsi Jawa Timur bisa mencapai angka 98\% (RPJMN 2015-2019) untuk cakupan tablet Fe-1 yaitu Kabupaten Trenggalek, Kabupaten Lumajang, Kabupaten Pasuruan, Kabupaten Sampang, Kabupaten Jember, Kota Madiun, Kota Surabaya, Kabupaten Blitar, Kota Mojokerto, Kabupaten Madiun, dan Kabupaten Magetan, sedangkan untuk cakupan tablet Fe-3 tidak ada Kabupaten/Kota di Provinsi Jawa Timur mencapai target tersebut. Dalam penelitian Litasari (2014) disebutkan jumlah ibu hamil yang mengonsumsi tablet $\mathrm{Fe}$ sebanyak 90 tablet sebesar $85,7 \%$ dengan peningkatan kadar $\mathrm{Hb} \geq 11$ gr/dl. Penelitian Fanny (2012) juga menyebutkan jumlah ibu hamil yang mengonsumsi tablet Fe sebanyak 90 tablet sebesar $93,3 \%$ dan terjadi peningkatan kadar $\mathrm{Hb}$ sebelum konsumsi tablet Fe dan sesudah konsumsi tablet Fe. Untuk meningkatkan cakupan tablet $\mathrm{Fe}$ diperlukan promosi kepada masyarakat (Tumaji,2014). Depkes RI (2008) menyebutkan bahwa promosi kepada masyarakat dapat dilakukan melalui pelayanan Antenatal Care, peningkatan kemitraan, dan kerja sama dengan sektor lain di samping itu diperlukan pengerahan masyarakat dalam menciptakan lingkungan yang mendukung program tersebut terkait dalam melakukan KIE (Komunikasi Informasi Edukasi) dan KIP-K (Komunikasi Inter Personal Konseling).

\section{Hubungan Cakupan ANC dan Prevalensi Anemia Ibu Hamil}

Berdasarkan hasil analisis dengan menggunakan uji statistik korelasi pearson. Cakupan K1 dengan prevalensi anemia menghasilkan nilai koefisien korelasi sebesar $\mathrm{r}=-0,109$. Cakupan $\mathrm{K} 4$ dengan prevalensi anemia menghasilkan nilai koefisien korelasi sebesar $\mathrm{r}=-0,115$.

Hasil cakupan ANC tampak adanya korelasi negatif yang mempunyai arti semakin tinggi cakupan kunjungan ibu hamil $\mathrm{K} 1$ dan $\mathrm{K} 4$, maka semakin menurun prevalensi anemia ibu hamil. 


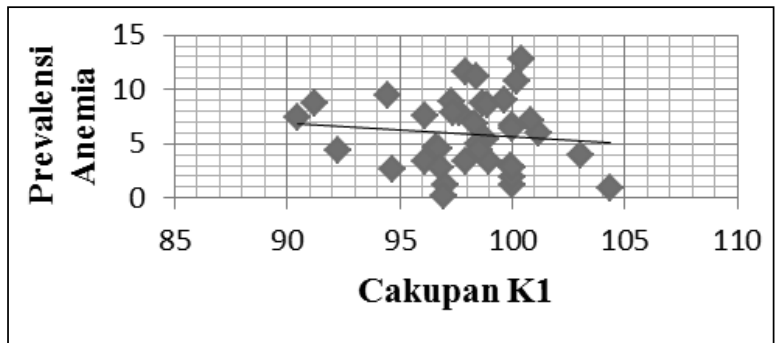

Gambar 6. Hubungan Cakupan K1 dengan Prevalensi Anemia Ibu Hamil di Propinsi Jawa Timur tahun 2015.

Hal ini sejalan dengan penelitian yang dilakukan Subarda (2011) yang menyebutkan bahwa ibu hamil yang mendapat pelayanan Antenatal Care (ANC) tidak baik/kurang mempunyai peluang 1,82 kali lebih tinggi untuk tidak patuh minum tablet $\mathrm{Fe}$ dibandingkan dengan ibu hamil yang mendapat pelayanan ANC yang baik. Dengan demikian, ibu hamil yang tidak mendapat pelayanan ANC standar akan berakibat pada ketidak patuhan mengonsumsi tablet $\mathrm{Fe}$ sehingga dapat meningkatkan risiko terjadinya anemia.

Hasil p-value $>0,05$ pada cakupan K1 dan $\mathrm{K} 4$ dengan prevalensi anemia yang berarti tidak signifikan atau tidak bermakna. Hal ini menunjukkan tidak ada hubungan antara cakupan $\mathrm{K} 1$ dan K4 dengan prevalensi anemia ibu hamil. Hal ini sejalan dengan penelitian yang dilakukan Sumaiku (2013) yang menyebutkan tidak ada hubungan Antenatal Care (ANC) dengan kejadian anemia pada ibu hamil. Amiruddin (2004) pada penelitiannya menyatakan bahwa frekuensi ANC tidak berhubungan dengan kejadian anemia pada ibu hamil. Berbeda dengan hasil penelitian oleh Husnah (2012) yang menunjukkan adanya hubungan antara pelayanan ANC dengan kebiasaan mengkonsumsi tablet Fe. Studi yang dilakukan oleh Brabin (1998) menyimpulkan bahwa intervensi gizi yang berfokus pada suplemen zat besi bermanfaat, namun masih belum bisa menekan angka prevalensi anemia pada kehamilan sehingga masih diperlukan pedoman kebijakan nasional untuk intervensi di bidang lain. Pelayanan Antenatal Care (ANC) dalam pengelolaan anemia merupakan serangkaian kegiatan yang meliputi pemeriksaan atau diagnosis anemia, pemberian tablet Fe, dan konsultasi gizi. Bidan berperan dalam mendukung peningkatan konsumsi tablet $\mathrm{Fe}$.
Tetapi, kenyataannya pemberian tablet Fe belum efektif menurunkan prevalensi anemia. Alasan utama kurang efektif adalah rendahnya kepatuhan ibu hamil dalam mengonsumsi tablet $\mathrm{Fe}$.

\section{Hubungan Cakupan Tablet Fe dan Prevalensi Anemia Ibu Hamil}

Berdasarkan hasil analisa dengan menggunakan uji statistik korelasi pearson, cakupan tablet Fe-1 dengan prevalensi anemia menghasilkan nilai koefisien korelasi sebesar $\mathrm{r}=0,125$. Cakupan Fe-1 dan Fe-3 menunjukkan adanya korelasi positif yang mempunyai arti kecenderungan semakin tinggi cakupan tablet $\mathrm{Fe}$, maka semakin tinggi prevalensi anemia ibu hamil. Hasil $p$-value $>0,05$ pada cakupan tablet Fe- 1 dan Fe-3 dengan prevalensi anemia ibu hamil yang berarti tidak signifikan atau tidak bermakna. Hal ini sejalan dengan penelitian yang dilakukan oleh Hasanah (2012) yang menyebutkan tidak ada hubungan yang signifikan antara asupan tablet $\mathrm{Fe}$ dengan kejadian anemia pada kehamilan. Dalam Puspasari (2008) dijelaskan bahwa faktor yang mempengaruhi kepatuhan ibu hamil mengonsumsi tablet $\mathrm{Fe}$ antara lain ketepatan jumlah, ketepatan cara mengonsumsi, dan frekuensinya.

Menurut Handayani (2015), alasan ibu hamil tidak patuh mengonsumsi tablet Fe karena faktor bosan, lupa dan kurangnya dukungan dari keluarga. Kautshar (2013) juga menyebutkan bahwa alasan ibu hamil tidak mengonsumsi tablet Fe disebabkan karena alasan lupa sebanyak 33 responden $(47,8 \%)$ dan 5 responden $(7,2 \%)$ karena malas minum obat. Penelitian oleh Muhilal (1996) menyebutkan cakupan tablet $\mathrm{Fe}$ dapat dipengaruhi oleh kepatuhan ibu hamil mengonsumsi tablet Fe. Penelitian mengenai kebiasaan ibu hamil mengonsumsi tablet $\mathrm{Fe}$ menggunakan air teh sebagai faktor inhibitor dilakukan oleh Sulistyaningsih (2015) yang menyebutkan 53\% ibu hamil mengonsumsi tablet $\mathrm{Fe}$ menggunakan air teh, menggunakan air putih sebanyak $40 \%$, dan menggunakan air jeruk sebanyak 7\%. Hasil penelitian tersebut menunjukkan konsumsi tablet Fe dipengaruhi biovailabilitas zat besi yang sangat dipengaruhi oleh faktor enhancers (penambah) dan inhibitor (penghambat) dalam makanan. 


\section{KESIMPULAN DAN SARAN}

Berdasarkan hasil penelitian dan pembahasan dapat disimpulkan bahwa rata-rata prevalensi anemia ibu hamil di Provinsi Jawa Timur sebesar $5,8 \%$. Angka prevalensi tersebut sudah ada dibawah target Nasional sebesar 28\%. Hasil uji statistik menunjukkan tidak ada hubungan antara cakupan ANC (K1 dan K4) dan cakupan tablet $\mathrm{Fe}(\mathrm{Fe}-1$ dan $\mathrm{Fe}-3)$ dengan prevalensi anemia ibu hamil.

Saran perlu dilakukan peningkatan pengetahuan bagi tenaga kesehatan mengenai anemia dengan tujuan menggerakkan masyarakat dan ibu hamil dalam upaya memanfaatkan fasilitas kesehatan

\section{DAFTAR PUSTAKA}

Agustini, N.Y.M., Suryani, N., Murdani, P. (2013). Hubungan Antara Tingkat Pengetahuan Ibu dan Dukungan Keluarga dengan Cakupan Pelayanan Antenatal di Wilayah Kerja Puskesmas Buleleng I. Jurnal Magister Kedokteran Keluarga, 1(1), 67-69.

Amiruddin. (2004). Studi Kasus Hubungan Kontrol Faktor Biomedis terhadap Kejadian Anemia Ibu Hamil di Puskesmas Bantimurung Maros Tahun 2004. Jurnal Medika Unhas, 3(2), 1-7.

Brabin, L., Nicholas, S., Gogate, A., Karande, A. (1998). High Prevalence of Ananemia Among Women in Mumbai India. Food and Nutritional Bulletin, 19(3), 1-102. Diakses dari www.nzdl. org

Departemen Kesehatan RI. (2010). Pedoman Pelayanan Antenatal Terpadu. Jakarta: Bina Kesehatan Masyarakat. Diakses dari Departemen Kesehatan RI. (2015). Data dan Informasi Tahun 2014 (Profil Kesehatan Indonesia). Jakarta; Bina Kesehatan Masyarakat. Diakses dari http://www.depkes.go.id//.

Dinas Kesehatan Provinsi Jawa Timur. (2012). Profil Kesehatan Provinsi Jawa Timur Tahun 2011. Surabaya: Dinas Kesehatan Provinsi Jawa Timur. Diakses dari http://www.depkes. go.id//.

Fanny, L., Mustamin, H., Dewi, T., Kartini, Hj. (2012). Pengaruh Pemberian Tablet Fe Terhadap Kadar Hb Ibu Hamil di Puskesmas Tamamaung tahun 2011. Jurnal Media Gizi Pangan, 13(1), 7-11.
Fitrayeni, Suryati, Faranti, R.,M. (2015). Penyebab Rendahnya Kelengkapan Kunjungan Antenatal Care Ibu Hamil di Wilayah Kerja Puskesmas Pegambiran. Jurnal Kesehatan Masyarakat Andalas, 10(1), 101-107.

Litasari, D., Sartono, A.,Mufnaetty. (2014). Kepatuhan Minum Tablet Zat Besi dengan Peningkatan Kadar Hb Ibu Hamil di Puskesmas Purwoyoso Semarang. Jurnal Gizi Universitas Muhammadiyah Semarang, 3(2), 25-33.

Husnah. (2012). Hubungan Pengetahuan, Sikap dan Antenatal Care dengan Konsumsi Tablet Besi pada Ibu Hamil di Puskesmas Ulee Kareng Kareng Banda Aceh. Jurnal Kedokteran Syiah Kuala, 12(3), 127-131.

Handayani, L.(2015). Peran Petugas Kesehatan dan Kepatuhan Ibu Hamil Mengonsumsi Tablet Besi. Jurnal Kesmas, 7(2), 83-88.

Hasanah, U. (2012). Hubungan Asupan Tablet Besi dan Asupan Makanan dengan Kejadian Anemia Pada Kehamilan di Puskesmas Mojo Tengah Kabupaten Wonosobo tahun 2012. (Skripsi, Universitas Indonesia, Jakarta). Diakses dari lib.ui.ac.id/file/20318196

Hidayat, W., Anasari, T. (2012). Hubungan Kepatuhan Ibu Hamil Mengonsumsi Tablet Fe dengan Kejadian Anemia di Desa Pageraji Kecamatan Cilongok Kabupaten Banyumas. Jurnal Ilmiah Kebidanan, 3(2), 41-53.

Irawati, E. (2012). Gambaran Keterpaduan Program KIA dan Gizi dalam Pelaksanaan Distribusi Tablet Fe Ibu Hamil di Puskesmas Perawatan Pagatan Kabupaten Tanah Bumbu Propinsi Kalimantan Selatan. (Skripsi, Universitas Indonesia, Jakarta). Diakses dari lib.ui.ac.id/ file/20319818

Kautshar, N. (2013). Kepatuhan Ibu Hamil Dalam Mengonsumsi Tablet Zat Besi (Fe) di Puskesmas Bara-Baraya Tahun 2013. Jurnal Gizi dan Pangan, 2(1), 12-21

Kementerian Kesehatan RI. (2014). Profil Kesehatan Indonesia Tahun 2013. Jakarta: Bina Kesehatan Masyarakat. Diakses dari http://www.depkes. go.id $/ /$.

Kementerian Kesehatan RI. (2013). Rencana Kerja Pembinaan Gizi Masyarakat Tahun 2013. Jakarta: Dirjen Bina Gizi dan KIA. Diakses dari http://www.dekpes.go.id//.

Muhilal, Sumarno, Komari. (1996). Ironsupplementation programmes: Compliance of target groups and frequency of tablet intake. 
Food and Nutrition Bulletin, 17(1), 1-92. Diakses dari www.nzdl.org.

Puspasari, F., D. Saryono, Ramawati, D. (2008). Faktor-Faktor yang Memengaruhi Kepatuhan Ibu Hamil dalam Mengonsumsi Tablet Besi di Desa Sokaraja Tengah Kecamatan Sokaraja Kabupaten Banyumas. Jurnal Keperawayan Soedirman, 3(1), 25-1.

Ritonga. (2012). Faktor-Faktor yang Memengaruhi Ibu Hamil dalam Melakukan Pemeriksaan Antenatal Care. Jurnal Keperawatan Klinis, $4(1), 1-5$.

Stoltzfus, R., Dreyfuss, M. (1998). Guidelines for The Use of Iron Supplements to Prevent and Treat Iron Deficiency Anemia. International Nutritional Anemia Consultative Group (INACG), Washington DC.

Sulistianingsih, Yanti, D.A.M., Ramadhan, R. (2015). Hubungan Ketepatan Waktu Konsumsi Tablet Besi dengan Kejadian Anemia Pada Ibu Hamil TM III. Jurnal Ilmu Keperawatan Indonesia, 5(4), 28-35.

Sumaiku,W. (2013). Hubungan Antenatal Care dan Suplementasi Fe dengan Anemia pada Ibu Hamil di Desa Sapa Kecamatan Tenaga Kabupaten Minahasa Selatan. (Skripsi, Universitas Sam
Ratulangi, Manado). Diakses dari fkm.unsrat. ac.id/2013/08

Subarda. (2011). Pelayanan Antenatal Care Dalam Pengelolaan Anemia Berhubungan Dengan Kepatuhan Ibu Hamil Minum Tablet. Jurnal Gizi Klinik, 8(1), 7-13.

Tumaji. (2014). Pemberian Tablet Zat Besi oleh Tenaga Kesehatan dan Kepatuhan Ibu Hamil Mengonsumsi Tablet Besi Lebih dari 90 Tablet yang Diperoleh dari Tenaga Kesehatan di Daerah Kumuh Perkotaan di Propinsi Jawa Barat dan Yogyakarta. Jurnal Buletin Penelitian Sistem Kesehatan, 17(3), 241-248.

Vita, K.M. (2014). Faktor-Faktor yang Berhubungan dengan Kekurangan Energi Kronis (KEK) pada Ibu Hamil di Kecamatan Kamoning dan Tambelengan Kabupaten Sampang Jawa Timur. Jurnal Penelitian Kesehatan Sistem Kesehatan, 17(2), 193-202.

WHO.(2001). Iron Deficiency Anaemia Assesment Prevention and Control a Guide Programme Managers., Geneva: WHO.

WHO. (2014). Global Nutrition Targets 2025: Anaemia Policy Bief. Geneva: WHO.

WHO. (2015). WHOStatistics. Geneva, Switzerland: WHO. 